\title{
Biological evaluation of selective laser melted magnesium alloy powder
}

\author{
ANDRZEJ PAWEŁ PAWLAK ${ }^{1 *}$, PATRYCJA EWA SZYMCZYK-ZIÓŁKOWSKA ${ }^{1}$, \\ ADAM JUNKA ${ }^{2}$, EDWARD CHLEBUS ${ }^{1}$ \\ ${ }^{1}$ Centre for Advanced Manufacturing Technologies, Wrocław University of Science and Technology, Wrocław, Poland. \\ ${ }^{2}$ Department of Pharmaceutical Microbiology and Parasitology, Wroclaw Medical University, Wrocław, Poland.
}

\begin{abstract}
Purpose: The current study examined magnesium alloy AZ31B specimens manufactured with Additive Manufacturing method (selective laser melting - SLM) to investigate the applicability of this technology for the production of medical devices. Methods: Osteoblast cells and bacterial biofilm growth ability on specimen was examined and the effect of surface state on corrosion resistance was evaluated by electrochemical and immersion methods. Results: High survival of hFOB cells, as well as a strong tendency for Pseudomonas aeruginosa and Staphylococcus aureus biofilm proliferation on the surface of the tested specimens were shown. SLM-processed AZ31B alloy has a higher corrosion resistance in $0.9 \% \mathrm{NaCl}$ solution and in a multi-electrolyte saline solution than the material in a conventional form of a rolled sheet. Conclusions: It has been demonstrated that the strong development of the surface of as-built processed specimens results in a significantly increased corrosion rate, which hinders the production of complex structures in tissue engineering products that support cell ingrowth.
\end{abstract}

Key words: selective laser melting, AZ31, biological evaluation, corrosion resistance, bacterial biofilm, biocompatibility

\section{Introduction}

Additive Manufacturing (AM) technologies have an advantage over conventional manufacturing technologies because they offer freedom in designing complex geometries, their application saves material usage and reduces lead time, especially in discrete manufacturing. Metal powder technologies are of particular importance among AM technologies. Thoroughly studied titanium (Ti-6Al-7Nb and Ti-6Al-4V) are titanium alloys with the highest amount of alloying elements (6\% of aluminium and 7\% nobium, and $6 \%$ aluminum and $4 \%$ of vanadium, respectively), stainless steel (SS) or cobalt chromium alloys (Co-Cr) are used to produce implants of complex porous structure facilitating bone tissue ingrowth, in particular knee and hip joints replacements, as well as medical instruments [8].
Magnesium and its alloys are materials gaining increasing interest among research groups regarding their potential use in medical applications. It is because of their excellent mechanical properties resembling those of bone tissue. Thanks to their resorbility, materials from this group may be removed from a tissue in non-invasive manner, and are gaining researchers' attentions as well like resorbable polymers [3], [32]. The first reports on potential applications of magnesium for production of resorbable implants were published at the beginning of the 20th century [36], however its wider use has been impeded because of too high and uncontrolled resorption rate. Despite the fact that $\mathrm{Mg}$ decomposes to form soluble, non-toxic corrosive hydroxide, the accelerated corrosion of this group of materials can lead to accumulation of gas pockets around the implant, which can cause loss of stability during the treatment process [14]. The attempts have been un-

\footnotetext{
* Corresponding author: Andrzej Paweł Pawlak, Faculty of Mechanical Engineering, Centre for Advanced Manufacturing Technologies, Wrocław University of Science and Technology, Wybrzeże Wyspiańskiego 27, 50-505, Wrocław, Poland. E-mail: andrzej.p.pawlak@pwr.edu.pl Received: August 18th, 2020

Accepted for publication: January 21st, 2021
} 
dertaken to reduce resorption rate and to improve material characteristics, both for biomedical and industrial applications, where metal corrosion is not desired. These approaches included modification of the chemical composition of magnesium-based alloys [7], [13] and the improvement of surface quality through the use of appropriate processing or treatment methods, including these performed by laser [27].

Owing to the process characteristics, additive technologies such as Selective Laser Melting (SLM) enable the researchers to obtain material of altered and desired characteristics. The above-mentioned, beneficial characteristics of magnesium alloys, which can be additionally modified by additive technologies during the manufacturing process, widen the application potential and open up new paths to the development of resorbable metal implants. The numerous studies on the development of the SLM technology for processing of magnesium alloys were conducted specifically for the purpose of their potential use in the production of medical devices [12], [22], [24]. These studies focused on the optimization of the process itself, whereas other studies aimed at the development of a method for the production of spatial structures, which allow cell to growth throughout the implant [11], [17]. However, there is still scarcity of data regarding the biological characteristics of magnesium alloys processed by means of additive technologies.

Therefore, the aim of this research was to examine the material produced by Selective Laser Melting (SLM) as a result of melting AZ31 magnesium alloy powder with a laser beam. The scope of described research was to evaluate laser processed material regarding its mechanical properties and its tendency to form a biofilm by $P$. aeruginosa and $S$. aureus strains on it.

\section{Materials and methods}

\section{Selective Laser Melting}

ReaLizer SLM50 (ReaLizer, Germany) printer was employed to produce the specimens used for the tests. The material used was magnesium alloy AZ31B (3\% Al, 1\% Zn) with 40-106 $\mu \mathrm{m}$ grain size (TLS Technik GmbH \& Co. Spezialpulver KG, Germany). Materials from the AZ group are considered promising owing to their improved anti-corrosion characteristics when used in combination with processing and surface modification technology [37]. All specimens were produced in argon shield with a layer thickness of $50 \mu \mathrm{m}$, using $75 \mathrm{~W}$ laser power and a scanning speed of $125 \mathrm{~mm} / \mathrm{s}$, which resulted in material porosity of $<0.5 \%$ [25]. Specimens for cytotoxicity, osteoblast and bacterial cell culture tests were steam sterilized at $120^{\circ} \mathrm{C}$.

Specimens for testing osteoblast and bacterial cell cultures, as well as cytotoxicity tests had a cylindrical shape $(\varnothing 6.2 \times 4 \mathrm{~mm})-$ Fig. 1 . Dimensions of the specimens were adjusted with respect to the size of the wells in the well plates used for the tests. $\varnothing 15 \times 2 \mathrm{~mm}$ disk-shaped specimens were used for electrochemical polarization corrosion tests. For immersion tests, cubic specimens with a volume of $1 \mathrm{~cm}^{3}$ were prepared, all walls of which were grinded using 1,000 grit sandpaper.

\section{hFOB culture}

1.19 hFOB growth potential was studied using cells from the ATCC CRL-11372 collection (American Type Culture Collection). Cells were pre-cultured in DMEM/HAM'S F12 MIX with L-glutamine and high glucose content medium, enriched with $10 \%$ fetal

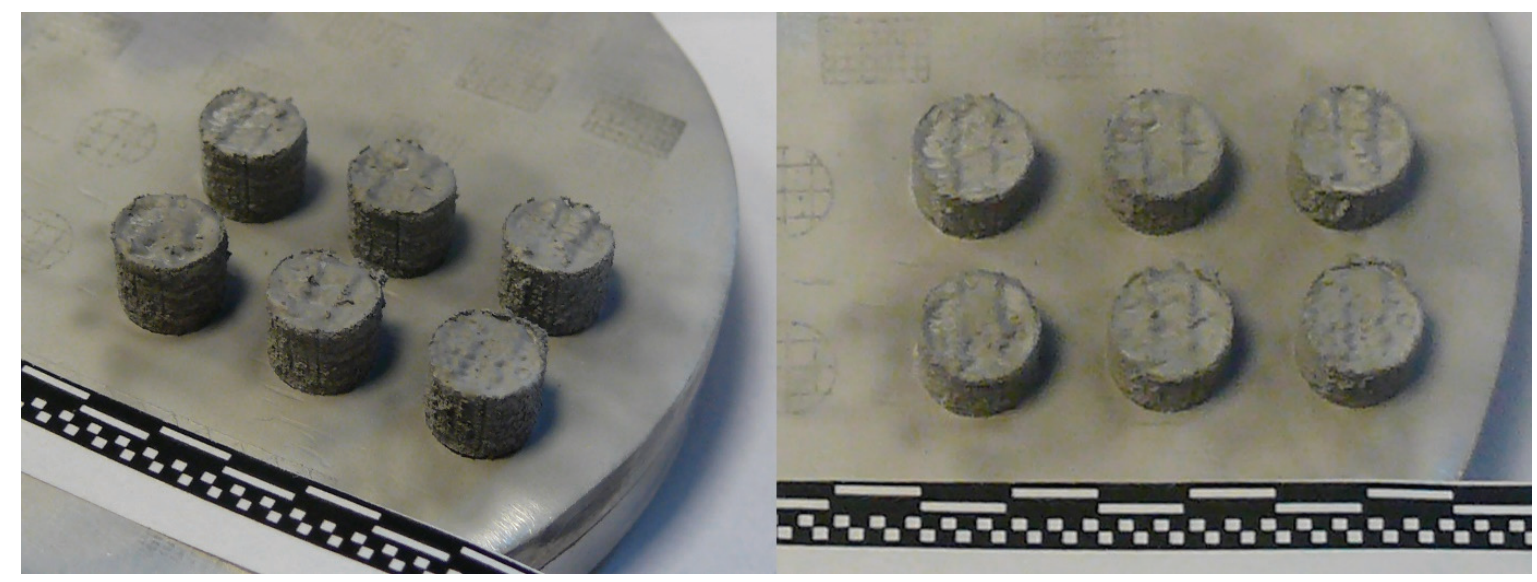

Fig. 1. Cylindrical specimens for microbiological tests and in vitro cell cultures produced by SLM technology 
serum, and penicillin-streptomycin/amphotericin B (BioWest, France) under aerobic conditions with the addition of $5 \% \mathrm{CO}_{2}$ at $37{ }^{\circ} \mathrm{C}$ and full humidity. The cultured single-layer colony was detached with trypsin and the number of cells was counted in a Bruckner chamber. Osteoblast density was determined at $1.5 \cdot 10^{5}$ cells $/ \mathrm{mL}$ ). Cell development was assessed by microscopy method using brightfield (Lumascope 620, Etaluma, SUA). Cell count was determined based on the NRU test in accordance with EN ISO 10993-5 and with use of Moxy Z cell counter. The applied NR (Sigma-Aldrich, Germany) concentration was $40 \mu \mathrm{g} / \mathrm{L}$.

Specimens made of the popular Ti-6Al-4V alloy processed by Electron Beam Melting technology using an Arcam A1 device (50 $\mu \mathrm{m}$ layer thickness, $45-100 \mu \mathrm{m}$ grain size powder (Arcam $\mathrm{AB}$ ) were used as a control for cytotoxicity studies.

\section{Cytotoxicity evaluation}

The manufactured specimens were immersed in $1 \mathrm{ml}$ of sterile cell culture medium containing fetal serum for $24 \mathrm{~h}$ under aerobic conditions with $5 \% \mathrm{CO}_{2}$ and full humidity at $37^{\circ} \mathrm{C}$. After the incubation period the specimens were removed and the medium they were incubated in was placed in the prepared osteoblast colony as previously described. Specimens were incubated for 24 and 48 hours, maintaining the culture conditions described. After the incubation, the medium was removed and the well plate was washed with saline solution, the wells were instilled with NR solution $(100 \mu 1 /$ well $)$ and incubated for 3 hours. The plates were then washed with PBS buffer and dried at room temperature. Then, $100 \mu 1$ of neutral red extraction solution was added to the wells and shaken for 25 minutes in the absence of light. Subsequently, the resulted supernatant containing NR in extraction solution $(50 \%$ ethanol (POCH, Wrocław, Poland), 49\% deionized water, $1 \%$ glacial acetic acid $(\mathrm{POCH}$, Wrocław, Poland) was analyzed using UVM-340 spectrometer (Multiscan Go, Thermo Fischer, USA) to determine the optical density for a $540 \mathrm{~nm}$ light wave. Cytotoxicity was assessed based on ISO 10993: Biological evaluation of medical devices - Part 5: Tests for in vitro cytotoxicity.

\section{Bacterial biofilm culture of $P$. aeruginosa and $S$. aureus}

Studies were carried out to assess the ability of bacteria most often causing inflammation after implantation at the implant site to form biofilm. Strains of Pseudomonas aeruginosa and Staphylococcus aureus (ATCC15442, ATCC6538, respectively) grown on solid media (McConkey, CA - Biocorp) were transferred to liquid media (TSB, BC - BioCorp) and incubated for $24 \mathrm{~h}$ at $37^{\circ} \mathrm{C}$ in an aerobic atmosphere without shaking. After the incubation period, the density of bacterial suspensions was determined by densinometry (Densimat, Biomerieux) at $3 \cdot 10^{8}$ cells $/ \mathrm{ml}$. The specimens were immersed in the suspension, incubated overnight at $37{ }^{\circ} \mathrm{C}$ and then washed with $0.9 \% \mathrm{NaCl}$ solution to remove unattached bacteria from the surface. The specimens were then placed in $1 \mathrm{ml}$ of $0.5 \%$ saponin detergent and shaken using a Vortex Lab Device Deco device to detach the bacterial biofilm. The detached suspension was diluted and each $100 \mu \mathrm{l}$ dilution was re-plated on the appropriate solid media (McConkey agar, Columbia agar for P. aeruginosa and $S$. aureus, respectively) and incubated for $24 \mathrm{~h}$ at $37^{\circ} \mathrm{C}$. After the incubation period, the number of bacterial colonies colonizing the tested specimens was counted. Results of quantitative microbiological tests were additionally confirmed by visualization of bacterial cells using electron microscopy (Zeiss EVO MA25, Germany). The microscopy procedure in accordance with the guidelines presented in other paper [37].

\section{Evaluation of biological corrosion}

Corrosion resistance was determined by electrochemical polarization in a three-electrode setup (working electrode: tested specimen, reference electrode: saturated $\mathrm{Ag} / \mathrm{AgCl}$ electrode, counter electrode: stainless steel). Scanning speed was $1 \mathrm{mV} / \mathrm{s}$.

The first tests assessed the impact of the surface quality on corrosion rate. Specimens were analyzed regarding three types of surface state: as-built, sandblasted with aluminium balls, and grinded with 1,000 grit sandpaper. The surface treatments reduced the surface Ra from the initial $39 \mu \mathrm{m}$ to 35 and $2 \mu \mathrm{m}$, respectively. Studies on the impact of surface quality on corrosion rate were carried out in $0.9 \% \mathrm{NaCl}$ solution in distilled water and at ambient temperature $\left(20-22^{\circ} \mathrm{C}\right)$.

In the next test, corrosion rate of grinded SLMed AZ31B alloy was evaluated at $37{ }^{\circ} \mathrm{C}$ (the solutions were heated using a thermostat heater with $\pm 0.5^{\circ} \mathrm{C}$ accuracy). The effect of two solutions: $0.9 \% \mathrm{NaCl}$ in distilled water and multi-electrolyte saline solution (Fresenius Optilyte), which was chosen because the content and concentration of element ions in the solution is similar to the content of natural blood plasma (Table 1), was analyzed. An additional argument for the choice of this specific solution was the lowest content of chlorine ions which was also closest to that of the blood plasma. 
Table 1. Different solutions and their ion composition for in vitro testing in $\mathrm{mmol} / \mathrm{dm}^{3}$

\begin{tabular}{|c|c|c|c|c|c|c|}
\hline $\begin{array}{c}\text { Ion } \\
\text { component }\end{array}$ & $\begin{array}{c}\text { Blood } \\
\text { plasma [29] }\end{array}$ & SBF [19] & $\begin{array}{l}\text { Optilyte - multi-electrolyte } \\
\text { saline solution }\end{array}$ & $\begin{array}{l}\text { Ringer's } \\
\text { solution }\end{array}$ & $0.9 \% \mathrm{NaCl}$ & $\begin{array}{l}\text { Hank's } \\
\text { solution }\end{array}$ \\
\hline $\mathrm{NA}^{+}$ & 142 & 142 & 141 & 147.2 & 153.9 & 142 \\
\hline $\mathrm{K}^{+}$ & 5 & 5 & 5 & 4 & & 5.8 \\
\hline $\mathrm{MG}^{2+}$ & 1.5 & 1.5 & 1 & & & 0.8 \\
\hline $\mathrm{CA}^{2+}$ & 2.5 & 2.5 & 2 & 2.2 & & 2.5 \\
\hline $\mathrm{CL}^{-}$ & 103 & 148.8 & 109 & 155.7 & 153.9 & 145 \\
\hline $\mathrm{HCO}_{3}$ & 27 & 4.2 & & & & 4.2 \\
\hline $\mathrm{HPO}_{4}$ & 1 & 1 & & & & 0.4 \\
\hline $\mathrm{SO}_{4}$ & 0.5 & 0.5 & & & & 0.8 \\
\hline $\mathrm{CH}_{3} \mathrm{COO}^{-}$ & & & 34 & & & \\
\hline $\mathrm{C}_{6} \mathrm{H}_{507}^{3-}$ & & & 3 & & & \\
\hline
\end{tabular}

\section{Evaluation of resorption capacity in vitro}

Static immersion tests were conducted to determine corrosion rate in accordance with ASTM-G31-72 standard practice over a period of 35 days. Specimens were washed in distilled water and dried with compressed air. After weighing and determining each of the specimens, they were placed in glass containers filled with $0.9 \% \mathrm{NaCl}$ and a multi-electrolyte saline solution to the volume corresponding to a ratio of $20 \mathrm{ml}$ solution $/ 1 \mathrm{~cm}^{2}$ of specimen surface. The solutions were kept at $37{ }^{\circ} \mathrm{C}$ throughout the test period (they were heated with a thermostat heater). The temperature and $\mathrm{pH}$ of the solution were recorded with a $\mathrm{pH}$ meter (CP-411, Elmetron).

At pre-defined time points, specimens were removed from the solution, washed in distilled water, dried and weighed, and surface changes were recorded using a confocal microscope. After the lapse of immersion period, corrosion products were removed from the specimens by immersion in chromic acid $\left(180 \mathrm{~g} / \mathrm{dm}^{3} \mathrm{CrO}_{3}\right)$ for 10 minutes, in line with ASM. Following acid digestion, the specimens were washed in distilled water, air dried and weighed to determine the actual mass loss and calculate resorption rate in accordance with ASTM-G31-72 in mm/year:

$$
\text { Corrosion rate }=\frac{K W}{A T D}
$$

where: $K$ - constant according to value units (for $\mathrm{mm} /$ year $\left.K=8.76 \cdot 10^{4}\right), T$ - exposure time [h], $A-$ specimen surface $\left[\mathrm{cm}^{2}\right], W-$ mass loss $[\mathrm{g}], D-$ density $\left[\mathrm{g} / \mathrm{cm}^{2}\right]$, acc. to standard annex, for $\mathrm{Mg} D=1.74$ ).

For reference, changes in $\mathrm{pH}$ of the osteoblast growth medium solution were measured with a specimen made of the analyzed alloy introduced in the solution. Specimens were introduced into $2 \mathrm{ml}$ of afore- mentioned osteoblast growth medium - for a 7-day incubation period in aerobic atmosphere containing $5 \% \mathrm{CO}_{2}$ at $37{ }^{\circ} \mathrm{C}$. Osteoblast growth medium was used as an experiment control $[K]$, to which no magnesium specimens were introduced. Changes in $\mathrm{pH}$ were read every 24 hours using the DuoTest pH 1-12 kit (Macherey-Nagel, GmbH \& Co.).

\section{Results}

\section{hFOB culture}

The AZ31 specimens produced by SLM demonstrate good biocompatibility. Over three weeks of studies, osteoblast proliferation showed a linear trend of ingrowth (Fig. 2). Compared to titanium specimens produced using EBM which is used for the production of medical devices, after 21 days of incubation, the

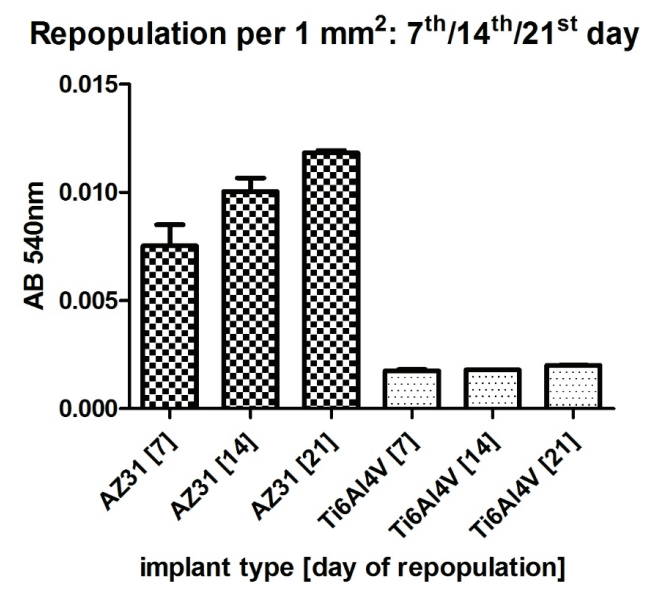

Fig. 2. Repopulation of human osteoblasts on specimens manufactured by AM 
number of cells proliferated on the surface of the specimens was higher for the specimens of the analyzed AZ31 alloy. In Figure 3, a network of osteoblast cultured on the surface of analyzed specimens from the AZ31 alloy produced using SLM technology after 7 days of culture is shown. Also no significant morphological changes of osteoblasts were observed under microscopic examination.

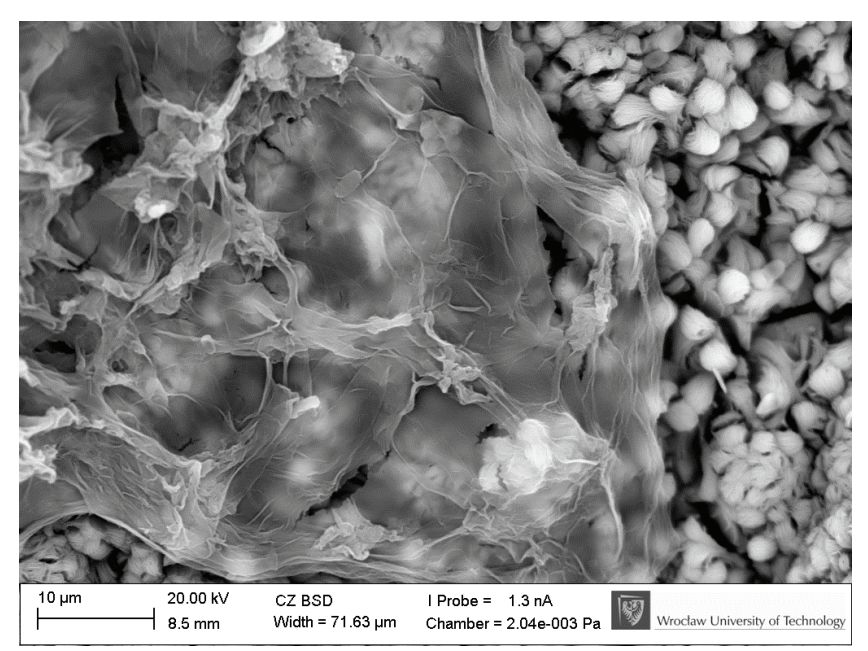

Fig. 3. Human osteoblast net cultured on the surface of the analyzed specimen (AZ31, SLM, 7th day). SEM image

\section{Cytotoxicity evaluation}

The results of optical density measurements of osteoblasts on the surface of SLM processed specimens are shown in Table 2. In both analyzed periods, the number of cells was lower than the control specimen. Regarding qualitative morphological grading of cytotoxicity of extracts, the morphological changes after 24 hours of incubation were assessed as grade 0 or 1 ; and as grade 1 after 48 hours of incubation. The viability of cells treated with AZ31B was $\sim 90 \%$ after 24 hours of incubation and $\sim 80 \%$ after $48 \mathrm{~h}$ of incubation in accordance with the requirements of ISO 10993: Biological evaluation of medical devices-Part 5: Tests for in vitro cytotoxicity cited. The results indicate that the material processed by SLM displays no cytotoxic effect ( $<30 \%$ drop of cell viability).

Table 2. Cell count after 24 and $48 \mathrm{~h}$ incubation period. The untreated cell culture served as positive control setting with viability considered $100 \%$

\begin{tabular}{|l|c|c|c|c|}
\hline $\begin{array}{c}\text { Specimen } \\
\text { type }\end{array}$ & $\begin{array}{c}\text { Viability } \\
{[\%]}\end{array}$ & $\begin{array}{c}\text { Cytotoxicity } \\
\text { evaluation } \\
24 \mathrm{~h}^{*}\end{array}$ & $\begin{array}{c}\text { Viability } \\
{[\%] 48 \mathrm{~h}}\end{array}$ & $\begin{array}{c}\text { Cytotoxicity } \\
\text { evaluation } \\
48 \mathrm{~h}\end{array}$ \\
\hline AZ31B & 89.4 & Nontoxic & 77.85 & Nontoxic \\
\hline Ti-6Al-4V & 93.7 & Nontoxic & 77.95 & Nontoxic \\
\hline
\end{tabular}

\section{$P$. aeruginosa and $S$. aureus bacterial biofilm culture}

The number of bacterial colonies in the biofilm formed on the AZ31 alloys surface was on average $5.42 \cdot 10^{9}\left( \pm 5.54 \cdot 10^{9}\right)$ and $4.42 \cdot 10^{8}\left( \pm 3.06 \cdot 10^{8}\right)$ for $P$. aeruginosa and $S$. aureus, respectively. Compared to the corresponding studies conducted on scaffolds produced from Ti-6Al-7 $\mathrm{Nb}$ alloy, the number of microorganisms was even 700 times higher [33].
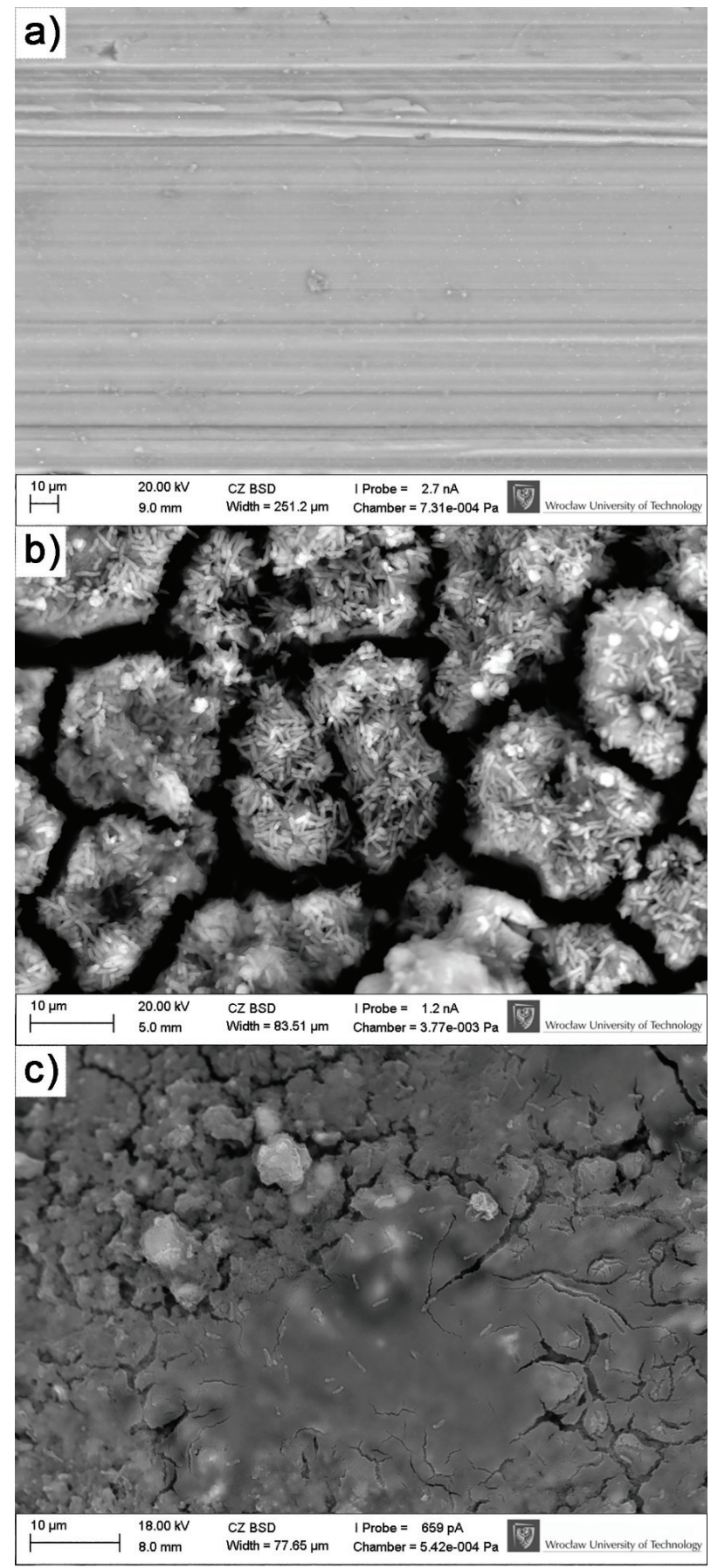

Fig. 4. P. aeruginosa biofilm on the surface of AZ31 specimens: a) sample surface before culture, b) after 7 days, c) after 21 days, SEM 
Table 3. Bacterial cell count in a biofilm cultured on specimen surface and reference titanium scaffolds

\begin{tabular}{|l|c|c|c|c|}
\hline \multicolumn{1}{|c|}{ Specimens } & \multicolumn{2}{|c|}{ Pseudomonas aeruginosa ATCC 15442 } & \multicolumn{2}{c|}{ Staphylococcus aureus ATCC6 538 } \\
\hline Scaffold SLM - Ti6Al7Nb [33] & $3 \times 10^{7}$ & $57331 \mathrm{cfu} / \mathrm{mm}^{2}$ & $2.33 \times 10^{9}$ & $3.08 \times 10^{6} \mathrm{cfu} / \mathrm{mm}^{2}$ \\
\hline Cylindrical specimen SLM - AZ31 & $5.54 \times 10^{9}$ & $39168072 \mathrm{cfu} / \mathrm{mm}^{2}$ & $4.42 \times 10^{8}$ & $2.2 \times 10^{6} \mathrm{cfu} / \mathrm{mm}^{2}$ \\
\hline
\end{tabular}

cfu-colony forming unit.

Table 4. Measured density of corrosion currents and corrosion potentials, as well as determined corrosion rate

\begin{tabular}{|l|c|c|c|c|}
\hline \multirow{2}{*}{ Specimen state } & \multirow{2}{*}{ Solution } & Corrosion rate & $E_{\text {corr }}$ & $I_{\text {corr }}$ \\
\cline { 3 - 5 } & & {$[\mathrm{mm} /$ year $]$} & {$[\mathrm{V}]$} & {$\left[\mu \mathrm{A} / \mathrm{cm}^{2}\right]$} \\
\hline AZ31 [16], [38] & $0.9 \% \mathrm{NaCl}, 20^{\circ} \mathrm{C}$ & 1.56 & $-1.587 \pm 0.02$ & 34.130 \\
\hline AZ31 $1_{\text {SLM }}$ as-built & $0.9 \% \mathrm{NaCl}, 20^{\circ} \mathrm{C}$ & $6.949 \pm 5.70$ & $-1.458 \pm 0.009$ & $831.940 \pm 285.77$ \\
\hline AZ31 $1_{\text {SLM }}$ sandblasted & $0.9 \% \mathrm{NaCl}, 20^{\circ} \mathrm{C}$ & $11.916 \pm 6.93$ & $-1.455 \pm 0.005$ & $955.723 \pm 121.22$ \\
\hline AZ31 $1_{\text {SLM }}$ grinded & $0.9 \% \mathrm{NaCl}, 20^{\circ} \mathrm{C}$ & $0.312 \pm 0.11$ & $-1.452 \pm 0.003$ & $18.632 \pm 3.79$ \\
\hline AZ31 ref. & $0.9 \% \mathrm{NaCl}, 37^{\circ} \mathrm{C}$ & 3.54 & -1.62 & 77.44 \\
\hline AZ31 & $0.9 \% \mathrm{NaCl}, 37^{\circ} \mathrm{C}$ & $1.023 \pm 0.60$ & $-1.434 \pm 0.017$ & $43.879 \pm 39.89$ \\
\hline AZ31 grinded & Optilyte, $37^{\circ} \mathrm{C}$ & $0.202 \pm 0.09$ & $-1.409 \pm 0.015$ & $8.673 \pm 5.90$ \\
\hline
\end{tabular}

Microscopic images clearly show that Pseudomonas aeruginosa forms a bacterial biofilm on the surface as early as after 7 days (Fig. 4a). After 21 days, bacterial colonies are much more developed, and the resulting biofilm is additionally cracked (Fig. 4b).

\section{Evaluation of biological corrosion}

The results of electrochemical measurements are summarized in Table 4. Tests have shown that corrosion rate for the SLMed grinded AZ31 was almost five times lower than the reference value (see Fig. 6).

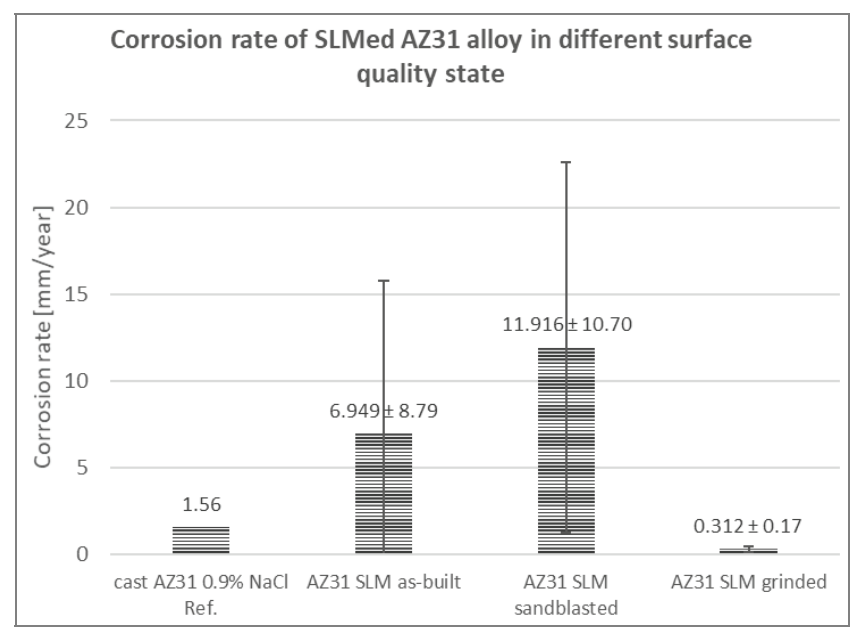

Fig. 5. Corrosion rate of SLMed specimens with different surface treatment states [16], [38]

Corrosion potential values $\left(E_{\text {corr }}\right)$ are lower (more resistant to corrosion) than the values reported in literature ([15], [39], Fig. 6) in each analyzed case of the specimen surface state. Despite the highly devel- oped surface shape and high surface roughness, the difference between the as-built and sanded surfaces is low, which indicates a slight improvement in corrosion resistance. Further improvement of surface quality by specimen grinding increases the corrosion resistance, but the results are not satisfactorily repeatable. Increasing the temperature of the solution increases the corrosion potential values, however, in the case of specimens produced in SLM, the change is not observable, while the use of multielectrolyte solution reduces the value of the corrosion potential.

Analysis of the values of the corrosion current density $\left(I_{\text {corr }}\right)$ clearly indicates the trend of lower corrosion resistance of the SLM processed material than the reference value (Fig. 6), as shown by higher measured values of $I_{\text {corr }}$. The only state that is distinguished is that after grinding, where the corrosion current values indicate an almost 3-fold increase in corrosion resistance compared to the reference material. Tests conducted in solutions with a temperature of $37{ }^{\circ} \mathrm{C}$ show a significant increase in the value of corrosion current, in the case of SLM specimens up to 2.5 times. The use of multi-electrolyte saline solution helped to obtain value of corrosion current almost twice lower compared to the values measured at room temperature for $0.9 \% \mathrm{NaCl}$ solution.

The determined corrosion rate values showed that for the grinded AZ31 material, the corrosion rate was almost five times lower than the reference value (Fig. 7). In the case of tests carried out in multi-electrolyte saline solution at higher temperature, the determined corrosion rate was $80 \%$ lower than for $0.9 \% \mathrm{NaCl}$ solution and as much as $95 \%$ lower than for the refer- 


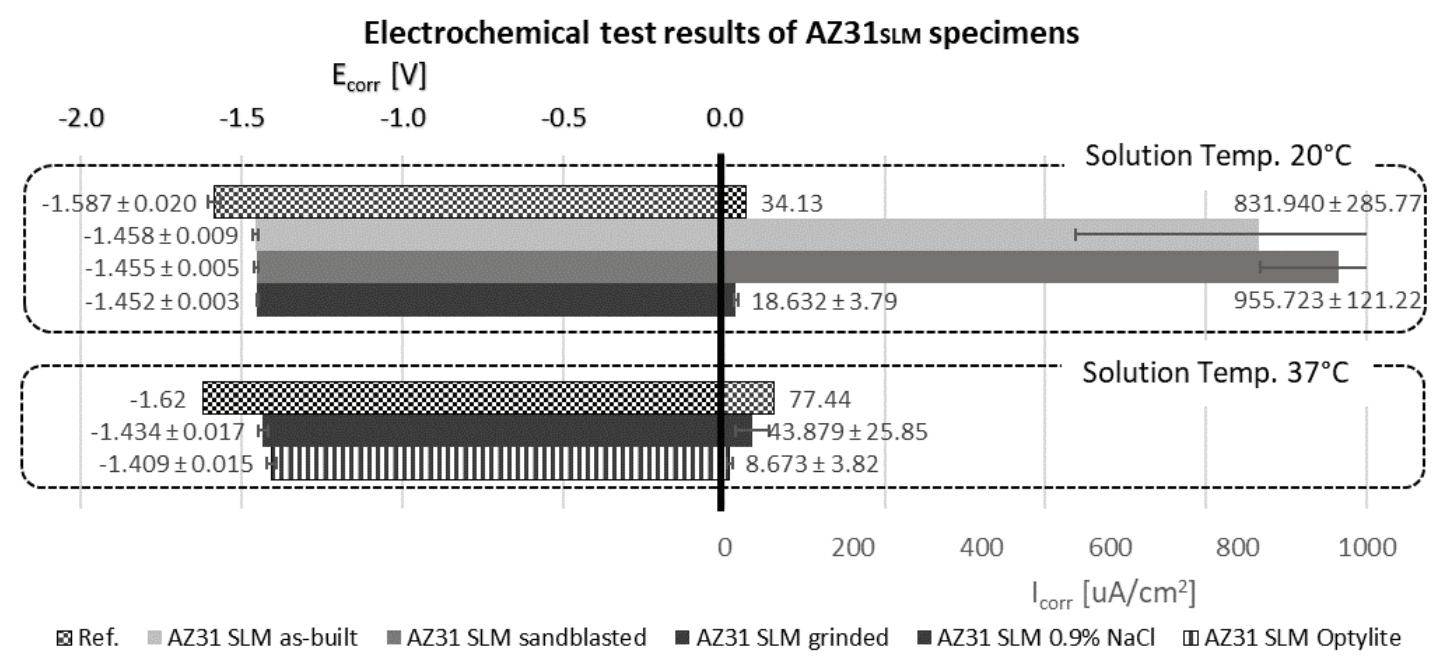

Fig. 6. Corrosion characteristics of specimens produced using SLM [16], [38]

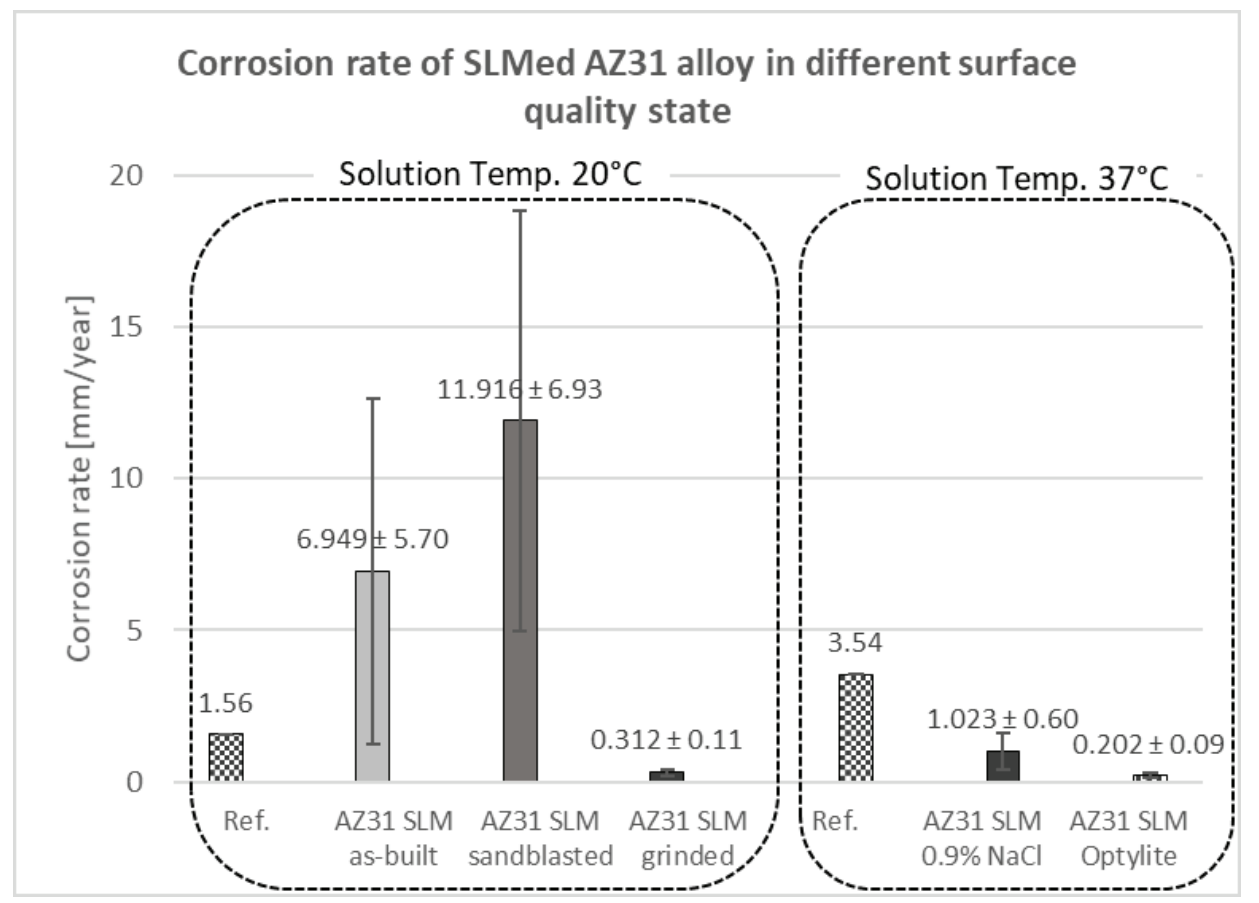

Fig. 7. Corrosion rates of AZ31 alloy specimens produced in SLM [16], [38]

ence material in $0.9 \% \mathrm{NaCl}$ solution and is only 0.202 $\pm 0.09 \mathrm{~mm} /$ year (Fig. 7).

\section{Evaluation of resorption capacity in vitro}

Corrosion rates determined in immersion tests are half lower than data from similar studies reported in literature for plastically processed material [16] (Table 5, Fig. 8). Additionally, three times lower resorption rate obtained in immersion tests in multi-electrolyte solution is worth noting.

The recorded change in mass over time does not indicate large digestion of the specimen in the ana- lyzed time period (Fig. 8). For specimens immersed in $0.9 \% \mathrm{NaCl}$ solution, the change in specimen mass is greater than for a multi-electrolyte solution. Attention should be paid to a very rapid increase of $\mathrm{pH}$ of both solutions, which was almost 10 within the first five hours and stabilized at this level for the remainder of the study. $\mathrm{pH}$ increase for the multielectrolyte solution was slightly lower than for $0.9 \%$ $\mathrm{NaCl}$.

Reference tests have shown that on the very next day $\mathrm{pH}$ of the solution with the immersed magnesium specimen increased to 8 and reached 10 after four days (Fig. 9). 
Table 5. Resorption rate determined after a 35-day immersion period

\begin{tabular}{|l|c|c|c|c|}
\hline & & Ref. $-0.9 \% \mathrm{NaCl}[16]$ & $0.9 \% \mathrm{NaCl}$ & $\begin{array}{c}\text { Optilyte }- \text { Multi-electrolyte } \\
\text { saline solution }\end{array}$ \\
\hline Mass loss & {$[\%]$} & n.a. & $13.13 \pm 3.5 \%$ & $4.25 \pm 2.3 \%$ \\
\hline Resorption rate & {$[\mathrm{mm} /$ year $]$} & 3.54 & $2.229 \pm 0.59$ & $0.706 \pm 0.37$ \\
\hline
\end{tabular}

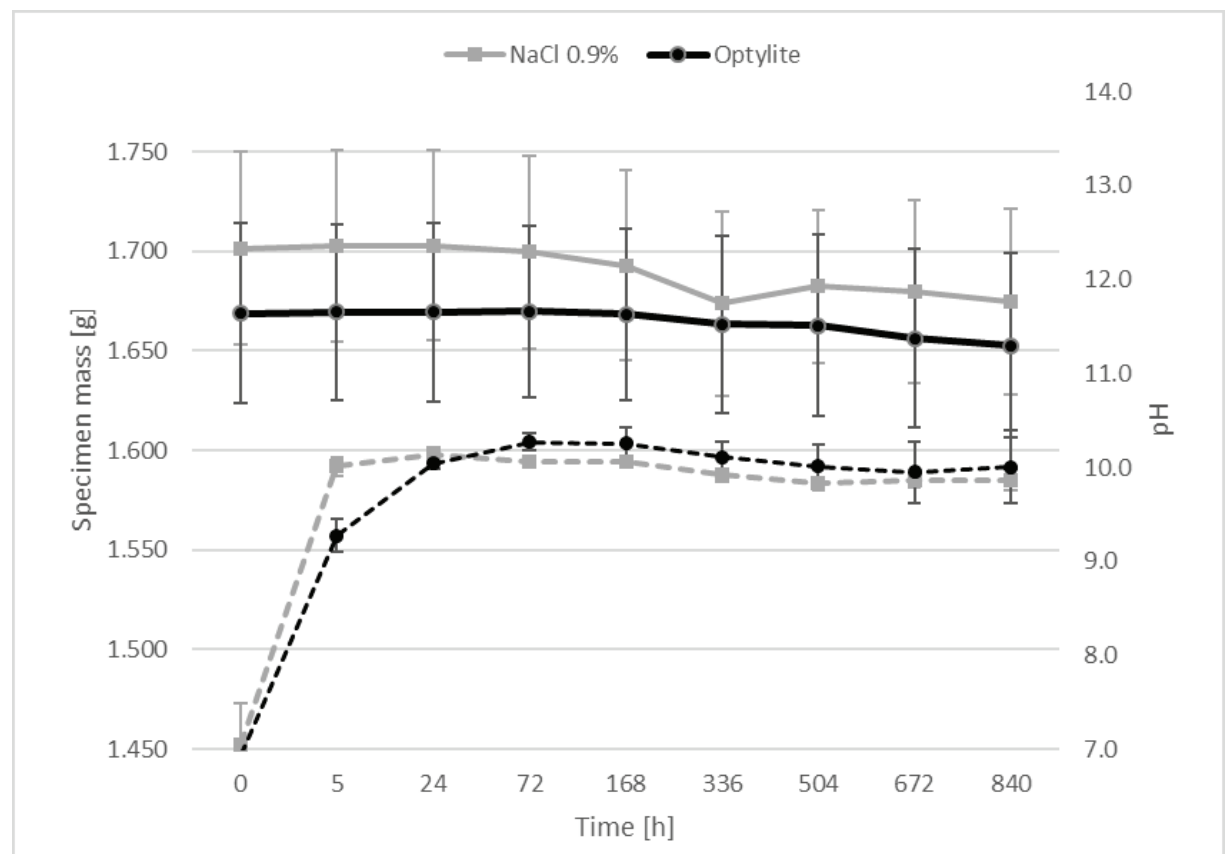

Fig. 8. Recorded change in specimen mass (left axis, solid lines) and $\mathrm{pH}$ of the solution over time (right axis, dashed lines)

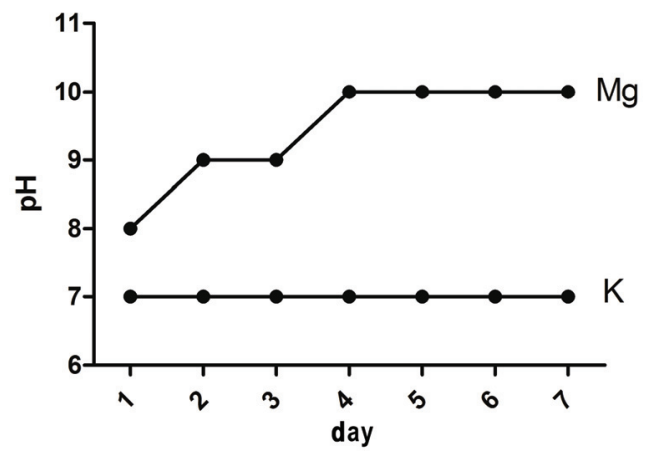

Fig. 9. $\mathrm{pH}$ of the medium with magnesium specimen produced by SLM $(\mathrm{Mg})$ and control $(K)$

\section{Discussion}

\section{hFOB culture and cytotoxicity evaluation}

Magnesium-based materials for implantation are biocompatibile and are able to built-up a functional interface implant-bone in osseointegration process [5], [6].

Tested in this paper samples made of AZ31 alloy processed in AM technology, display very good biocompatibility and no cytotoxicity against osteo-blast cell. As presented in Fig. 2, tested samples shown the above-mentioned properties superior to the titanium control being currently in clinical use. These findings were also described in referenced paper [5], and applied in this research novel additive processing method have not affected this process negatively. Obtained results are based on the fact that magnesium has a key role in osteoporosis healing and enhances osseointegration process in osteoporotic patients, and this element ions are also investigated in order to increase bone formation process on other metallic implants [10]. 


\section{P. aeruginosa and S. aureus bacterial biofilm culturing on manufactured AZ31 samples}

Strains of two bacteria, which are a common cause of chronic osteomyelitis, the disease which frequently requires application of implants [32], were selected for bacterial biofilm studies. Patients with immune system disorders and those undergoing invasive surgery, e.g., implantation are particularly susceptible to infection with these bacteria. Pseudomonas aeruginosa and Staphylococcus aureus have a high tendency to form a biofilm that can proliferate not only on living tissues, but also on the surfaces of such medical foreign objects as implants, stents, etc. [2].

The results from the culture of hFOB and P. aeruginosa and $S$. aureus bacterial strains show their high tendency to proliferate on the surfaces of implants. In the case of hFOB cells, a high proliferation rate on implant surface is desirable, whereas biofilm formation on implant surface leads to serious health complications and life threat. The results presented in this article indicate a high risk of etiological osteomyelitis after implantation of AZ31 alloy implants processed in SLM. Despite the high potential of the material in terms of mechanical properties and low cytotoxicity, this material seems to be also a surface on which Pseudomonas aeruginosa biofilm develops easily. Extrapolation of in vitro results presented inhere to the clinical conditions may indicate that non-preservation of hygienical measures during implantation may lead to biofilmrelated complications [40] and, in turn, to hinder the patient's full recovery.

Studies on strategies for eliminating bacterial biofilm on implants is one of the most important areas of interests nowadays. Surface modification options may help reduce the tendency of bacterial cells to proliferate on the surface of implants without compromising the ability of osteoblasts to repopulate [18], [33]. There are wide research on metals and their compounds abilities to combat bacteria and biofilms. It was examined that the efficacy in combat different bacterial strains depends on investigated metal compound, e.g., $\mathrm{Cu}$, Ti salts are most effective in preventing formation of $P$. aeruginosa, $S$. aureus and $E$. coli biofilms, but also is efficient in inhibiting planktonic cell growth [15]. The most commonly used antibacterial coatings involves silver ions and its nanoparticles which are biocompatible, but at the same time are expensive and could cause local cell toxicity [23]. Tsimbouri et al. reported also that use of $\mathrm{TiO}_{2}$ nanowires applied on implant surface inhibits $P$. aeruginosa proliferation on Titanium implants [35]. Another approach of fighting against biofilms is to use anti-biofilm molecules, mainly isolated from natural sources but also synthetic compounds, like enzymes, peptides, polyphenols, and also nanoparticles $[28,30]$. Peptide-modified surface of stainless steel was found to have the best efficacy against $S$. aureus after optimization of grinding procedure, using \#600 sandpaper [4].

Additional studies are needed into post-process treatment for AZ31 alloy produced in SLM technology, to reduce the propensity of $P$. aeruginosa bacterial strain to proliferate on the material in question.

\section{Evaluation of biological corrosion}

Corrosive characteristics were determined for three surface states to explore the potential of SLM, which enables production of complex spatial structures [26] impossible to produce using traditional machining methods, which also hinders improvement of surface quality in places inaccessible to tools (such as cutting/milling or abrasive tools). The characteristics of the SLM process allow the production of objects from powders that adhere to the surface of the objects, resulting in roughness of up to $\mathrm{Ra}=40 \mu \mathrm{m}$. Since it is impossible to satisfactorily improve the surface quality of freely shaped topologically optimized structures or scaffolds developed for medical purposes by blasting or chemical etching [20], it is necessary to use mechanical surface treatment such as, for instance, grinding. Low corrosion resistance of the SLMed as-built specimens resulting from the very complex surface area caused by high roughness, excludes the possibility of producing complex geometric structures, which significantly hinders production of scaffolding for cell colonizing or free geometries impossible to be improved by proper surface treatment, the production of which was attempted precisely for use in the production of medical devices [17], [21].

Subsequently, the corrosion behaviour of grinded specimens was tested at $37{ }^{\circ} \mathrm{C}$ and in $0.9 \% \mathrm{NaCl}$ and Optilyte multi-electrolyte solutions. This particular solution was chosen because its chlorine ion content was the lowest and closest to that of the blood plasma. The presence of $\mathrm{Cl}^{-}$ions in the solution promotes the transformation of magnesium hydroxide $\left(\mathrm{Mg}(\mathrm{OH})_{2}\right)$ into a soluble magnesium chloride $\left(\mathrm{MgCl}_{2}\right)$, which results in a higher content of $\mathrm{OH}^{-}$ions and higher $\mathrm{pH}$ [39]. A higher content of chlorine ions in the solution, when using Ringer's solution or SBF, could lead to results incomparable with in vivo conditions. However, according to literature reports, the results of corrosion tests conducted in vitro are still almost four orders of magnitude higher when it comes to corrosion rate than those determined in vivo [31]. However, considering different methods of measuring implant defect, one cannot unreservedly accept the authors' thesis that the 
implant's solubility in vivo cannot be inferred from in vitro studies.

In the case of both analyzed solutions, the SLM produced specimens subjected to the tests had better corrosion characteristics than the reference specimens. Lower corrosion rate may be the result of the material microstructure, which, like in the case of all SLM processed materials is characterized by high fragmentation [25], and is the goal of several treatments aimed at improved corrosion resistance [1], [9]. Studies reported by Taltavull on laser surface treatment of magnesium indicate that changes in corrosion resistance are affected to a greater extent by surface quality, internal stress in the material on the modified surface and its carburization than the induced changes in the microstructure [34].

\section{Evaluation of resorption capacity in vitro}

Increased $\mathrm{pH}$ value of the test solutions results from intensive emission of gases $(\mathrm{H})$ which are a byproduct of specimen digestion, which is manifested by strong turbidity of the solution (which is stronger for $\mathrm{NaCl}$ than for the Optilyte multi-electrolyte solution), observed in the first hours after the start of the test. Oxidation accelerates in electrolytic and humid environment. Corrosion of pure magnesium is accelerated at $\mathrm{pH}$ of 7.4-7.6 [31]. Oxides formed in this environ- ment are non-toxic and soluble, and then excreted in the urine. $\mathrm{pH}$ close to 10 was obtained in both solutions as early as after 24 hours. $\mathrm{pH}$ value in immersion tests increased faster than during incubation of osteoblast growth medium.

Over time, the specimens clearly degraded with pitting and defects visible in the specimen surface (Fig. 10), and a white buildup formed on the surface of the specimens, which might have been the result of deposition of $\mathrm{NaCl}$ contained in the solution. In view of the above, it would not be objective to determine periodic mass losses of specimens, and even more so resorption rates, due to growing areas of deposits on the surface of the specimens, which increased their mass. In the case of the analyzed magnesium alloy with a very low density $<2 \mathrm{~g} / \mathrm{cm}^{3}$ growing deposits on the specimens may make up for the loss resulting from magnesium oxidation. Higher content of $\mathrm{Cl}^{-}$ions in $0.9 \% \mathrm{NaCl}$ solution, in fact, in line with the theory, increases $\mathrm{pH}$ value as a result of decomposition of magnesium hydroxide and dissolution of magnesium chloride $\mathrm{MgCl}_{2}$, which explains faster disintegration of the test specimens [39].

Corrosion rate values determined from immersion tests were 2 times higher than from electrochemical tests for $0.9 \% \mathrm{NaCl}$ solution and 3.5 times higher than from multi-electrolyte solution (Fig. 11). This
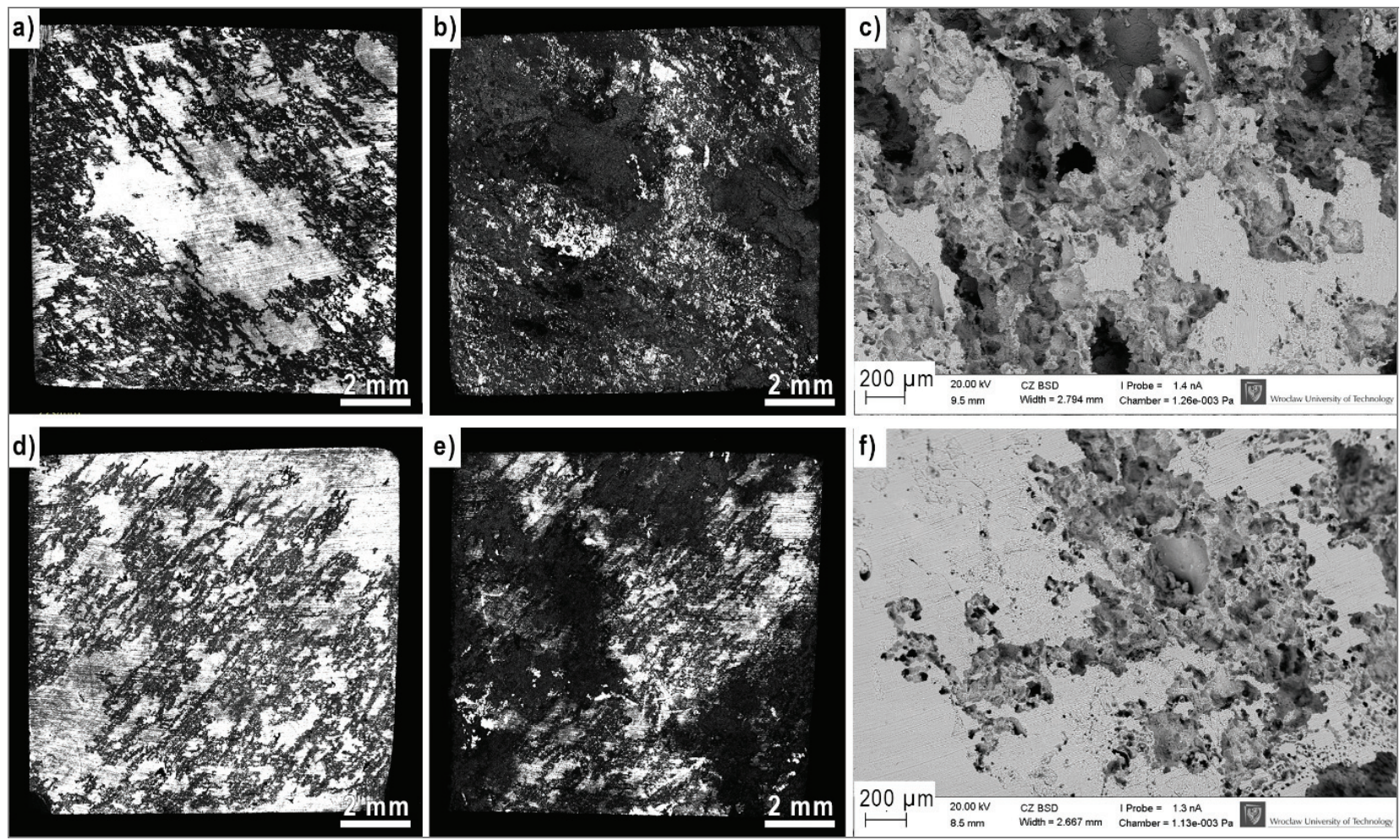

Fig. 10. Surface state osf specimens analyzed in immersion test: a)-c) $0.9 \% \mathrm{NaCl}$ solution,

d)-f) Optilyte solution, a), d) specimens after 5 hours' immersion in solutions, b), e) specimens after 28 days in the bath, c), f) SEM image of the surface of specimens after removal of corrosion products, $\times 100$ magnification 


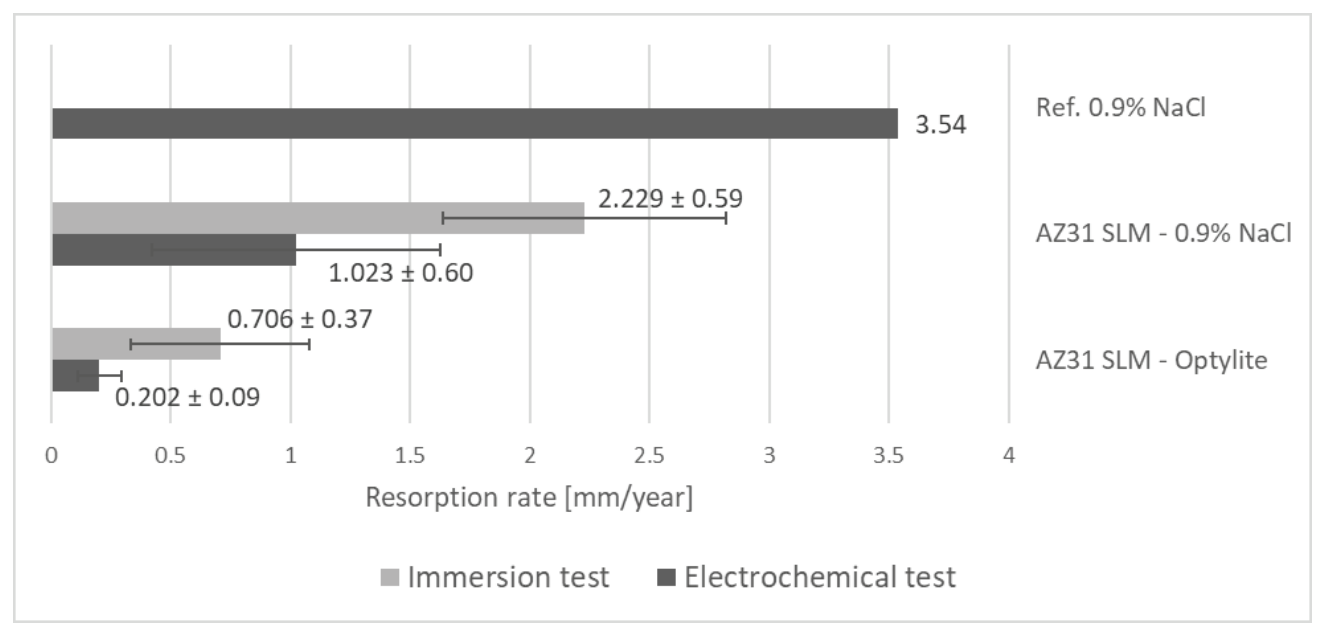

Fig. 11. Resorption rates determined from immersion tests in the analyzed solutions [16]

may be caused by the higher digestion rate of magnesium specimens following initial digestion of the surface layer and more active dissolution of the material.

\section{Conclusions}

The lack of data regarding biological evaluation and corrosion tests of additively processed magnesium-based materials, was a driver to conduct described research. The results discussed in the paper confirm that SLM technology offers new opportunities to process magnesium alloys (based on AZ31 alloy used for this study), especially in order to manufacture medical instruments. The results of the research led to the following conclusions:

1) biocompatibility studies have shown high cell survival in vitro;

2) specimens of SLM processed material colonized by bone cells (hFOB) promoted adhesion and multiplication of these cells;

3) bacterial cultures have also showed high tendencies to form a biofilm on the surface of the analyzed specimens. These studies point to an increased risk of infection and thus rejection of the implant and necessitate analysis of possible surface treatments to inhibit bacterial growth;

4) corrosion resistance of SLM processed magnesium alloy is higher than that of the material in the form of a rolled sheet only if surface treatment consisting of grinding is used;

5) corrosion rate determined during the immersion test is even 3.5 times higher than corrosion rate determined during electrochemical tests.

\section{References}

[1] Avvari M.S.N., ABle M., Microstructure evolution in AZ61 alloy processed by equal channel angular pressing, Adv. Mech. Eng., 2016, 8, 168781401665182, DOI: 10.1177/ 1687814016651820 .

[2] Buarnsholt T., Biofilm Infections, Springer Science, 2011.

[3] Bodnárová S., Gromošová S., Hudák R., Rosocha J., ŽivČÁk J., Plšíková J., VoJTKo M., Tóth T., Harvanová D., IŽARIKOVÁ G., DANIŠOviČ L., 3D-printed Polylactid Acid based porous scaffold for bone tissue engineering: an in vitro study, Acta Bioeng. Biomech., 2020, 21, DOI: 10.37190/ abb-01407-2019-02.

[4] CaO P., Li W.W., Morris A.R., Horrocks P.D., Yuan C.Q., YANG Y., Investigation of the antibiofilm capacity of peptidemodified stainless steel, R. Soc. Open Sci., 2018, 5, DOI: 10.1098/rsos.172165.

[5] Castellani C., Lindtner R.A., Hausbrandt P., Tschegg E., StANZl-TschegG S.E., ZANONI G., BeCK S., WeInBERG A.M., Bone-implant interface strength and osseointegration: Biodegradable magnesium alloy versus standard titanium control, Acta Biomater., 2011, 7, 432-440, DOI: 10.1016/ j.actbio.2010.08.020.

[6] Cheng P., Zhao C., Han P., Ni J., Zhang S., Zhang X., Chai Y., Site-Dependent Osseointegration of Biodegradable High-Purity Magnesium for Orthopedic Implants in Femoral Shaft and Femoral Condyle of New Zealand Rabbits, J. Mater. Sci. Technol., 2016, 32, 883-888, DOI: 10.1016/ j.jmst.2016.03.012.

[7] Chou D.T., Hong D., Saha P., Ferrero J., Lee B., Tan Z., Dong Z., KuMTA P.N., In vitro and in vivo corrosion, cytocompatibility and mechanical properties of biodegradable $\mathrm{Mg}-\mathrm{Y}-\mathrm{Ca}-\mathrm{Zr}$ alloys as implant materials, Acta Biomater., 2013, 9, 8518-8533, DOI: 10.1016/j.actbio.2013.06.025.

[8] Culmone C., Smit G., Breedveld P., Additive manufacturing of medical instruments: A state-of-the-art review, Addit Manuf., 2019, 27, 461-473, DOI: 10.1016/ j.addma.2019.03.015.

[9] Dziadoń A., Mola R., Magnesium - trends of development of mechanical properties, Inżynieria Mater w obróbce Plast XXIV, 2013, 253-277. 
[10] Galli S., Stocchero M., Andersson M., Karlsson J., He W., LiLin T., WENNERBERG A., JiMBo R., The effect of magnesium on early osseointegration in osteoporotic bone: a histological and gene expression investigation, Osteoporos. Int., 2017, 28, 2195-2205, DOI: 10.1007/s00198-017-4004-5.

[11] Gieseke M., NölKe C., KaierLe S., Maier H.J., Haferkamp H., Selective Laser Melting of Magnesium Alloys for Manufacturing Individual Implants, Fraunhofer Direct Digital Manufacturing Conference, 2014, 1-6.

[12] Gruber K., Mackiewicz A., Stopyra W., Dziedzic R., KURZYNOWSKI T., Development of manufacturing method of the MAP21 magnesium alloy prepared by selective laser melting (SLM), Acta Bioeng. Biomech., 2019, 21, 157-168, DOI: 10.5277/ABB-01472-2019-04.

[13] Gu X., Zheng Y., Cheng Y., Zhong S., Xi T., In vitro corrosion and biocompatibility of binary magnesium alloys, Biomaterials, 2009, 30, 484-498, DOI: 10.1016/ j.biomaterials.2008.10.021.

[14] Gu X., Zhou W.R., Zheng Y.F., Cheng Y., Wei S.C., ZHONG S.P., XI T.F., CHEN L.J., Corrosion fatigue behaviors of two biomedical Mg alloys - AZ91D and WE43 - in simulated body fluid, Acta Biomater., 2010, 6, 4605-4613, DOI: 10.1016/j.actbio.2010.07.026.

[15] Gugala N., Lemire J.A., Turner R.J., The efficacy of different anti-microbial metals at preventing the formation of, and eradicating bacterial biofilms of pathogenic indicator strains, J. Antibiot. (Tokyo), 2017, 70, 775-780, DOI: 10.1038/ja.2017.10.

[16] Hadzima B., Mhaede M., Pastorek F., Electrochemical characteristics of calcium-phosphatized AZ31 magnesium alloy in $0.9 \% \mathrm{NaCl}$ solution, J. Mater Sci. Mater Med., 2014, 25, 1227-1237, DOI: 10.1007/s10856-014-5161-0.

[17] JAUER L., JÜLICH B., Voshage M., MeInERS W., Selective Laser Melting of magnesium alloys, Eur. Cells Mater, 2015, 30.

[18] Junka A.F., Szymczyk P., Secewicz A., Pawlak A., SMUTNickA D., ZióŁkowski G., BARTOSZEwicz M., Chlebus E., The chemical digestion of Ti6Al7Nb scaffolds produced by selective laser melting reduces significantly ability of Pseudomonas aeruginosa to form biofilm, Acta Bioeng. Biomech., 2016, 18, 105-110, DOI: 10.5277/ABB00333-2015-01.

[19] Konubo T., TaKadama H., How useful is SBF in predicting in vivo bone bioactivity?, Biomaterials, 2006, 27, 29072915, DOI: 10.1016/j.biomaterials.2006.01.017.

[20] LyCzkowska E., SzymczyK P., Dybala B., Chlebus E., Chemical polishing of scaffolds made of Ti-6Al-7Nb alloy by additive manufacturing, Arch. Civ. Mech. Eng., 2014, 14, 586-594, DOI: 10.1016/j.acme.2014.03.001.

[21] Matena J., Petersen S., Gieseke M., Teske M., Beyerbach M., Kampmann A., Escobar H., Gellrich N.-C., HaferkamP H., Nolte I., Comparison of Selective Laser Melted Titanium and Magnesium Implants Coated with PCL, Int. J. Mol. Sci., 2015, 16, 13287-13301, DOI: 10.3390/ijms160613287.

[22] Ng C.C., Savalani M.M., Man H.C., Gibson I., Layer manufacturing of magnesium and its alloy structures for future applications, Virtual Phys. Prototyp, 2010, 5, 13-19, DOI: $10.1080 / 17452751003718629$.

[23] Orapiriyakul W., Young P.S., Damiati L., Tsimbouri P.M., Antibacterial surface modification of titanium implants in orthopaedics, J. Tissue Eng., 2018, 9, DOI: 10.1177/ 2041731418789838.

[24] Pawlak A., Chlebus E., Szymczyk P., ZióŁkowski G., JUNKA A.F., Selective Laser Melting of Magnesium AZ31
Alloy for Future Medical Applications, Fraunhofer Direct Digital Manufacturing Conference 2016, Fraunhofer, Berlin, 2016, 379-383.

[25] Pawlak A., Szymczyk P., Kurzynowski T., Chlebus E., Selective laser melting of magnesium AZ31B alloy powder, Rapid Prototyp J., 2020, 26, 249-258, DOI: 10.1108/RPJ-052019-0137.

[26] Pawlak A., Szymczyk P., ZióŁKowski G., Chlebus E., DYBALA B., Fabrication of microscaffolds from Ti-6Al-7Nb alloy by SLM, Rapid Prototyp J., 2015, 21, 393-401, DOI: 10.1108/RPJ-10-2013-0101.

[27] Pu Z., Outeiro J.C., Batista A.C., Dillon O.W., Puleo D.A., JAWAHIR I.S., Enhanced surface integrity of AZ31B Mg alloy by cryogenic machining towards improved functional performance of machined components, Int. J. Mach. Tools Manuf., 2012, 56, 17-27, DOI: 10.1016/j.ijmachtools.2011.12.006.

[28] Roy R., Tiwari M., Donelli G., Tiwari V., Strategies for combating bacterial biofilms: A focus on anti-biofilm agents and their mechanisms of action, Virulence, 2018, 9, 522-554, DOI: 10.1080/21505594.2017.1313372.

[29] SAnchez A.H.M., Luthringer B.J.C., Feyerabend F., WiLlumeIt R., $M g$ and $M g$ alloys: How comparable are in vitro and in vivo corrosion rates? A review, Acta Biomater., 2015, 13, 16-31, DOI: 10.1016/j.actbio.2014.11.048.

[30] Shrestha A., Zhilong S., Gee N.K., Kishen A., Nanoparticulates for antibiofilm treatment and effect of aging on its antibacterial activity, J. Endod., 2010, 36, 1030-1035, DOI: 10.1016/j.joen.2010.02.008.

[31] Staiger M.P., Pietak A.M., Huadmai J., Dias G., Magnesium and its alloys as orthopedic biomaterials: A review, Biomaterials, 2006, 27, 1728-1734, DOI: 10.1016/ j.biomaterials.2005.10.003.

[32] Szewczenko J., Kajzer W., Kajzer A., Basiaga M., KACZMAREK M., ANTONOWICZ M., NOWIŃSKA K., JAWORSKA J., JELONEK K., KASPERCZYK J., Biodegradable polymer coatings on Ti6Al7Nb alloy, Acta Bioeng. Biomech., 2020, 21, DOI: 10.37190/abb-01461-2019-01.

[33] Szymczyk P., Junka A., ZióŁKowski G., Smutnicka D., Bartoszewicz M., Chlebus E., The ability of S.aureus to form biofilm on the TI-6Al-7Nb scaffolds produced by Selective Laser Melting and subjected to the different types of surface modifications, Acta Bioeng. Biomech., 2013, 15, 69-76, DOI: $10.5277 / \mathrm{abb} 130109$.

[34] Taltavull C., Torres B., Lopez A.J., Rodrigo P., Otero E., ATRENS A., RAMS J., Corrosion behaviour of laser surface melted magnesium alloy AZ91D, Mater Des., 2014, 57, 40-50, DOI: 10.1016/j.matdes.2013.12.069.

[35] Tsimbouri P.M., Fisher L., Holloway N., SJostrom T., Nobbs A.H., Meek R.M.D., Su B., Dalby M.J., Osteogenic and bactericidal surfaces from hydrothermal titania nanowires on titanium substrates, Sci. Rep., 2016, 6, 1-12, DOI: $10.1038 /$ srep36857.

[36] WitTE F., Reprint of: The history of biodegradable magnesium implants: A review, Acta Biomater., 2015, 23, S28-S40, DOI: 10.1016/j.actbio.2015.07.017.

[37] Witte F., Hort N., Vogt C., Cohen S., Kainer K.U., WillumeIt R., FEYERABEND F., Degradable biomaterials based on magnesium corrosion, Curr. Opin. Solid State Mater Sci., 2008, 12, 63-72, DOI: 10.1016/j.cossms.2009.04.001.

[38] Zeng R., Chen J., Dietzel W., Hort N., Kainer K.U., Electrochemical behavior of magnesium alloys in simulated body fluids, Trans. Nonferrous Met. Soc. China, 2007, 17, 166-170. 
[39] Zhang S., Zhang X., Zhao C., Li J., Song Y., Xie C., Tao H., Zhang Y., He Y., JiAng Y., Bian Y., Research on an Mg-Zn alloy as a degradable biomaterial, Acta Biomater., 2010, 6, 626-640, DOI: 10.1016/j.actbio.2009.06.028.
[40] Zuluaga A.F., Galvis W., Saldarriaga J.G., Agudelo M., Salazar B.E., Vesga O., Etiologic Diagnosis of chronic Osteomyelitis A Prospective Study, Arch. Intern. Med., 2006, 166, 95-100. 